Instituto Internacional para la Unificación del Derecho Privado (2019). Principios UNIDROIT sobre los Contratos Comerciales Internacionales. 2016. Edición preparada por la Pontificia Universidad Católica de Valparaíso. Valparaíso: Ediciones Universitarias de Valparaíso.

Desde su creación en el año 1994, los Principios Unidroit sobre Contratos Comerciales Internacionales han experimentado una continua ampliación a través de las sucesivas ediciones aparecidas en los años 2004, 2010 y 2016. Es esta última la que ahora se presenta en una nueva publicación realizada por la Pontificia Universidad Católica de Valparaíso de la mano de Álvaro Vidal Olivares y Rodrigo Momberg Uribe.

La edición chilena toma como base el trabajo realizado por un grupo de académicos compuesto por Javier Rodríguez Olmos (Colombia), Núria Bouza Vidal (España), José Moreno Rodríguez (Paraguay), Jorge Oviedo Albán (Colombia), Pedro Mendoza Montano (Guatemala) y Eugenio Hernández Bretón (Venezuela), quienes se han encargado de la traducción de las normas y comentarios de la versión 2016. Este equipo de trabajo ha realizado su labor bajo la dirección de Alejandro Garro (Argentina, Universidad de Columbia), quien ha estado a cargo de la versión en español de este instrumento desde su creación el año 1994.

Estos Principios son el más importante instrumento elaborado por el Instituto Internacional para la Unificación del Derecho Privado, organismo con sede en Roma cuyo propósito es el estudio de las necesidades y métodos para la modernización, armonización y coordinación del derecho privado entre Estados. Creado el año 1926, el organismo actual cuenta con 63 países miembros, ocupando su atención en temas de procedimiento civil, propiedad intelectual, mercado de valores y contratos, entre otros, destacando por la creación de cuerpos codificados destinados a armonizar y actualizar estas distintas áreas del derecho. Al menos en nuestro país, los Principios sobre Contratos Comerciales Internacionales son la obra más conocida de esta institución. 
El inmenso prestigio y calidad técnica de los juristas colaboradores de dicho organismo internacional ha hecho a los Principios Unidroit un referente obligado para los estudiosos del denominado "nuevo derecho de los contratos", así como para los operadores jurídicos que requieren de una normativa moderna y consciente de la realidad de la contratación internacional. Si bien no se trata de un tratado internacional, su amplia aceptación ha llevado a su aplicación, ya sea por voluntad expresa de las partes o como un elemento auxiliar de interpretación e integración de los contratos comerciales internacionales.

Tal como señalan Álvaro Vidal y Rodrigo Momberg en su prefacio, los Principios Unidroit gozan de aceptación y aplicación universal, influencia de la que Chile no ha estado exento. En efecto, la dogmática del derecho civil los ha utilizado continuamente como modelo para efectos de realizar una relectura de las normas sobre contratos del Código Civil chileno. Asimismo, muchas de sus soluciones han servido de base a disposiciones del proyecto de Principios Latinoamericanos de Derecho de los Contratos, iniciativa que ha ido cobrando cada vez mayor importancia en nuestro medio.

La publicación que rescensionamos tiene el mérito de presentar en lengua castellana no solo la traducción oficial de los artículos (black-letter rules), sino que, además, se han traducido los comentarios oficiales (los cuales hasta hoy están disponibles únicamente en inglés y en francés en el sitio web de Unidroit). La importancia de estos comentarios es que interpretan, explican y desarrollan las disposiciones, lo que, sin duda, constituye una herramienta útil desde un punto de vista tanto propedéutico como práctico, puesto que estos comentarios deben entenderse, por indicación de Unidroit, como parte integrante del texto normativo.

La principal novedad que presentan los Principios UNIDROIT en su versión 2016 es la inclusión de una serie de normas, o menciones dentro de normas ya existentes, aplicables a los que se denominan contratos de larga duración, definidos en el art. 1.11 como aquellos "cuyo cumplimiento se extiende en el tiempo y que suele involucrar, en mayor o menor medida, una operación compleja y una relación continuada entre las partes". Tal como señala el comentario a su definición estos contratos se contraponen a los contratos ordinarios de intercambio, como la compraventa, dentro de los cuales pueden incluirse, a modo ejemplar, la agencia comercial, los contratos de distribución, franquicia, arrendamiento, construcción, hasta otras figuras asociativas como los acuerdos de inversión o los joint ventures.

Dentro de la definición de contrato de larga duración, se indica como la nota esencial de estos la extensión, siendo la complejidad de la operación y la relación continuada entre las partes elementos que pueden estar presentes o no. Por ende, habrá que atender a cada norma y comentario en particular para determinar en qué medida deben concurrir estos elementos adicionales a la duración para revisar su procedencia o cómo se aplican al caso concreto. Si bien los Principios Unidroit captan que en la vida de los negocios internacionales 
existen claras diferencias entre los contratos de intercambio -caracterizados por una ejecución única o instantánea- y los contratos de larga duración, pareciera que los criterios esbozados para distinguir entre uno y otro es una cuestión que la norma no quiso zanjar de modo absoluto, dando cierta flexibilidad a la hora de determinar que normas son aplicables a cada contrato en particular. En ese sentido, no debe entenderse la inclusión de la categoría de contrato de larga duración como la creación una summa divisio de los contratos, sino que como una flexibilización de ciertas instituciones para adaptarla a las necesidades del tráfico.

Dentro de las normas y comentarios que se han modificado en la versión 2016 de los Principios para hacer mención a los contratos de larga duración, son especialmente relevantes los que se refieren a los contratos con términos abiertos (art. 2.1.14), a las circunstancias relevantes para la interpretación e integración del contrato (arts. 4.3 y 4.8), a la determinación de los deberes de las partes y del contenido del contrato (arts. 5.1.3, 5.1.4 y 5.1.7), la resolución en los contratos de tiempo indefinido (art. 5.1.8), a la fuerza mayor como eximente de responsabilidad (art. 7.1.7), a los efectos de la resolución por incumplimiento (art. 7.3.5) y las restituciones que se deben producto de esta resolución (art. 7.3.7).

En particular, resulta cuestionable que la traducción al castellano use el concepto de resolución para referirse tanto a un caso de desistimiento unilateral (como es el art. 5.1.8) como a otro que es de modo propio uno de resolución por incumplimiento (art. 7.3.5). Lo anterior se debe probablemente a una traducción poco adecuada del texto en inglés, el cual usa el concepto termination en ambos supuestos, siendo este lo suficientemente amplio como para incluir hipótesis de incumplimiento y de desistimiento unilateral. Podría haberse seguido aquí el ejemplo de la traducción italiana, la cual habla en el art. 5.1.8 de recesso, reservando el término risoluzione para la extinción del contrato cuyo origen está en el incumplimiento de una de las partes.

Fuera de las modificaciones anotadas, el texto conserva la estructura ya definida por la edición del año 2010, la cual, además de un preámbulo, contiene once capítulos destinados a disposiciones generales (I), formación del consentimiento y actuación por medio de representantes (II), cuestiones de validez y nulidad (III), interpretación e integración (IV), contenido del contrato $(\mathrm{V})$, cumplimiento $(\mathrm{VI})$, incumplimiento, con las acciones y derechos del contratante diligente (VII), compensación (VIII), cesión de créditos y contratos (IX), prescripción $(\mathrm{X})$ y casos con pluralidad de acreedores y deudores (XI).

Junto con el texto y sus comentarios, la presente publicación incluye los documentos oficiales preparados por Unidroit que acompañan a las versiones disponibles en su sitio web, consistentes en los prólogos e introducciones a las ediciones anteriores, muy relevantes a efectos de entender e interpretar las disposiciones de conformidad al espíritu con el que fueron creadas en su momento. Se incluye, además, una tabla de correspondencia de la ubicación de los artículos en las distintas ediciones, lo que permite identificar el año de introducción o modificación de cada una de las normas. 
Además de estos documentos, se ha agregado a esta edición impresa un apéndice con el texto de los artículos o black-letter rules, lo que facilita la lectura del núcleo normativo de los Principios. Podría haberse agregado un segundo apéndice con las normas en inglés, tal como se ha hecho en otras ediciones latinoamericanas (como la preparada por el Centro de Estudios de Derecho Comparado de la Universidad de La Sabana). Considerando que uno de los propósitos del Instituto Internacional para la Unificación del Derecho Privado es tender puentes entre distintas regulaciones estatales, muchas decisiones sobre los conceptos o procedimientos siguen al acervo de una u otra tradición jurídica, por lo que recurrir al texto en inglés resulta fundamental a la hora de realizar un estudio a cabalidad de los alcances de las normas, por lo que es lamentable que no se haya incluido su texto en esta edición.

Echamos de menos también el que no se haya incluido un apéndice con las cláusulas modelo propuestas por Unidroit para el uso de los Principios en la práctica contractual, existiendo solo una remisión al sitio web del organismo que las contiene. Si bien la omisión se entiende por ser esta una obra realizada con el apoyo de Unidroit, el cual debe velar por que exista uniformidad entre las distintas versiones, gran cantidad de remisiones hechas en los comentarios a las cláusulas modelo hubiera justificado la innovación.

Por último, se ha agregado un índice analítico, el cual incluye los términos más relevantes en sus diferentes usos y aplicaciones. Las referencias son hechas 364 tanto a los artículos como a la parte del respectivo comentario que trata el punto en específico, lo que se agradece atendida la extensión de ciertas disposiciones y sus sendas explicaciones.

Finalmente, no cabe sino agradecer a Álvaro Vidal y Rodrigo Momberg, a la Pontificia Universidad Católica de Valparaíso y a Unidroit por haber permitido e impulsado la publicación en Chile de esta edición completísima en español de los Principios sobre Contratos Comerciales Internacionales en su versión del año 2016, la cual, sin duda, permitirá una mayor difusión y estudio de este instrumento de armonización del derecho de los contratos en el ámbito latinoamericano. Esperamos que, asimismo, sea inspiradora de proyectos similares relativos a otros textos e iniciativas internacionales de la misma índole.

\section{SigLAS Y ABREVIATURAS}

art. artículo

arts. artículos

Unidroit Instituto Internacional para la Unificación del Derecho Privado

Francisco Álvarez Werth ${ }^{1}$

\footnotetext{
${ }^{1}$ Abogado. Licenciado en Derecho por la Pontificia Universidad Católica de Chile. Alumno regular del Programa de Doctorado en Derecho Universidad de los Andes.
} 